\title{
STUDY OF THREE-POINT LINKAGE OF POWER MACHINE
}

\author{
Judit PÁSZTOR, ${ }^{1}$ Izolda POPA-MÜLLER ${ }^{2}$ \\ ${ }^{1}$ Sapientia Hungarian University of Transylvania, Târgu-Mureș, Romania, pjudit@ms.sapientia.ro \\ ${ }^{2}$ Sapientia Hungarian University of Transylvania, Târgu-Mureș, Romania, ipmuller@ms.sapientia.ro
}

\begin{abstract}
The three-point linkage serves to interconnect the power machine and the suspended or semi-suspended work machine. It has a role in the operation of the machine group, in towing and in the setup of the machines. Part of the weight of the suspended machine is loaded on the driven wheels, thus increasing the adhesion weight which results in an increase in the tractive force. Understanding the operation of this equipment it is necessary for horticulture, agronomy and landscape architecture future engineers. In this thesis we model the effect of connection points of the three-point linkage on the tractive force in a specific case: that of the suspended plow.
\end{abstract}

Keywords: three-point linkage, adhesion weight force.

\section{Introduction}

\subsection{Tractive force of the agricultural power machine}

Agricultural power machines are capable of exerting traction and providing energy suitable for work machines. The operating goal is increasing the tractor's tractive force. The maximum tractive force is determined by the adhesion between the ground and the driven wheels:

$$
F_{\text {vmax }}=\mu \cdot G_{\text {adh }}[N] \text {, }
$$

where: $\quad \mu$ is the adhesion coefficient; $G_{a d h}$ adhesion weight force [N].

The adhesion weight force is the force exerted on the driven wheels of power machines. For universal tractors $2 / 3$ of the weight, for high-performance tractors $1 / 3$ of the weight is considered to be the adhesive weight, based on [1].

The maximum tractive force can be increased by increasing the adhesion factor or the adhesive weight force.

Possibilities for increasing the adhesive weight force:

- Additional weights can be attached to the driven wheels;

-With the four-wheel drive, the total weight of the power machine can be converted into adhesive weight force;
- By using a crawler tractor, the total weight can also be gained by adhesive weight force;

-Part of the weight of the machine suspended on the tractor will place load on the driven wheels, gaining it as adhesive weight force

In this dissertation we study the load of the suspended work machine on the driven wheel, which increases the adhesive weight force, thus causing an increase in tractive force during towing. The machine is suspended from the tractor with the three-point linkage.

\subsection{The three-point linkage of the power machine}

The three-point linkage device is a three-dimensional arm mechanism (Figure 1). It consists of the arm system and the lifting system.

The arm system consists of 1 lower links, 2 lift links and 3 lift arms. The lifting arms are connected by the rockshaft 4. A 5 upper link is also part of the arm system. The lower links are secured by 6 lateral limiters. The length of the lift links and upper link can be changed with an adjusting screw. The lifting system consists of a 7 hydraulic slave cylinder, a hydraulic pump and a control valve. The rockshaft can be rotated by inserting the hydraulic slave cylinder; thereby the attached machine can be raised or lowered. 
The connection of the two lower links and the upper link to the tractor can occur at two or three points (Figure 2).

The three-point linkage unifies the power machine-work machine group, based on [2]. The three-point linkage can be used to level the work machine horizontally. Part of the weight of the suspended machine increases the adhesive weight force, so it has a role in traction.

\section{Dynamic modeling of the three-point linkage}

The role of the three-point linkage in traction is studied in the power machine and suspended plough group, during plowing. We performed a dynamic modeling.

The dynamic model takes into account the forces acting on the machine group (Figure 3). The tested power machine and suspended work machine system cannot be described in its entirety taking into account all the interactions, therefore the emphasis is placed on the essential, based on [3]. During plowing, it can be assumed that the driver of the power machine prefers the fourwheel drive.

The adhesive weight force during a four-wheel drive can be interpreted as follows:

$$
G_{a d h}=R_{E}+R_{H}[N] .
$$

The equilibrium force system in the vertical plane is as follows:

$$
R_{E}+R_{H}-G_{T}-G_{E}-F_{z}+R_{K}=0[N],
$$

where:

$-R_{E}$ and $R_{H}$ are the soil resistances on the wheels of the tractor [N];

$-G_{T}$ is the weight of the tractor [N];

$-G_{E}$ is the plow weight [N];

$-F_{z}$ is the vertical component of soil resistance during plowing [N];

$-R_{K}$ is the soil resistance under the depth limit wheel of plough [N].

Transferring the weight of the suspended work machine to the driven wheels of the power machine results the change of the magnitude of the soil resistance $R_{K}$ that arises under the depth limit wheel of plough. We will calculate this force. We assume that the torque of the forces acting on the work machine at the vertical instantaneous pivot point $P$ are in equilibrium, based on [3]:

$$
\begin{aligned}
& -R_{K} \cdot\left(x+l_{K}+l\right)-f R_{K} \cdot h+G_{E} \cdot\left(x+l+l_{G}\right)+ \\
& \quad+F_{z} \cdot\left(x+l+l_{F}\right)-F_{X}\left(h_{F}+h\right)=0 .
\end{aligned}
$$

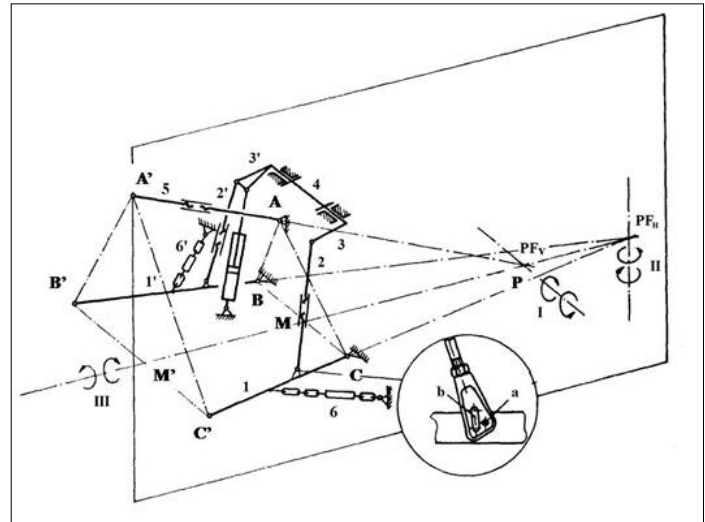

Figure 1. Scheme of the three-point linkage [2]
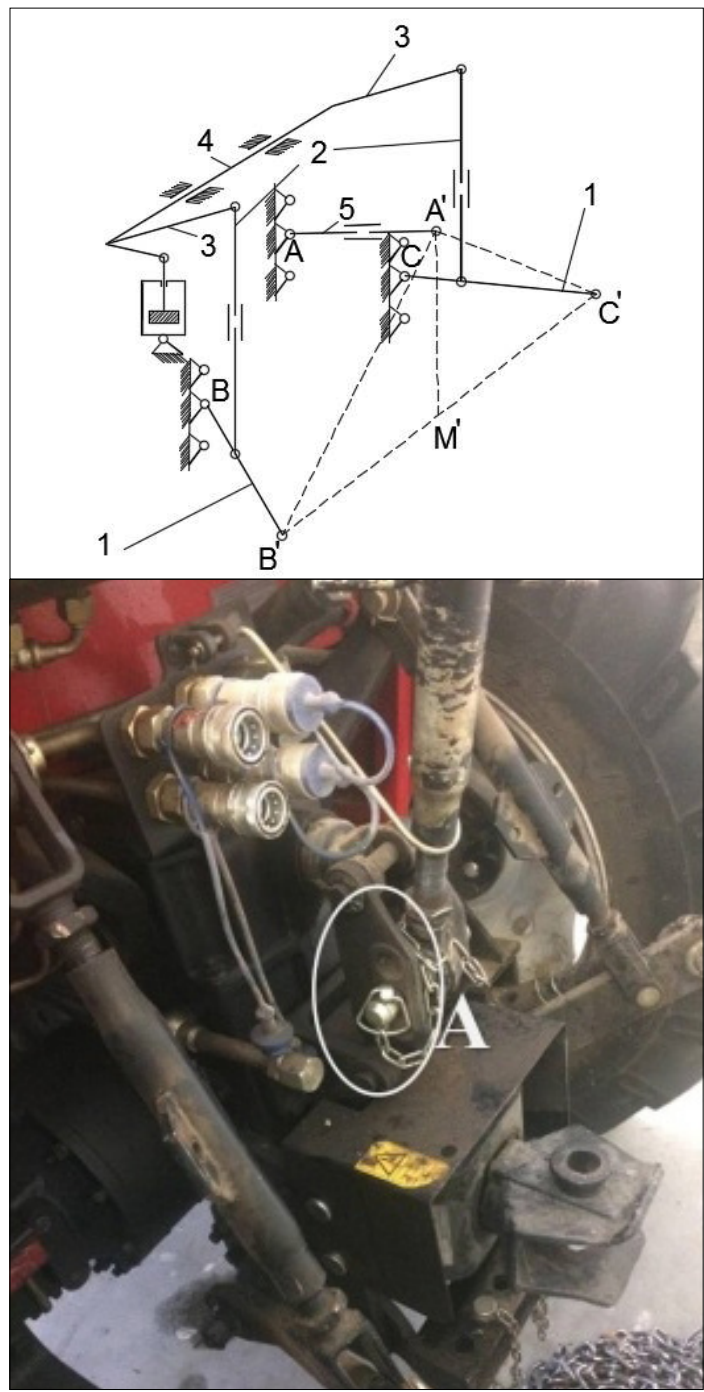

Figure 2. Different options for connecting the links of the three-point linkage 


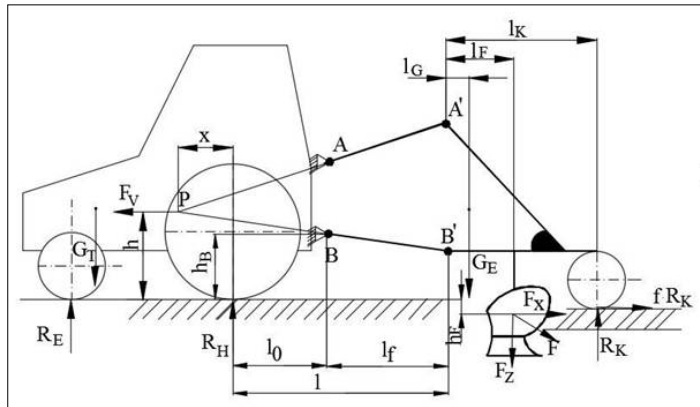

Figure 3. Forces on the tractor and suspended plough during towing.

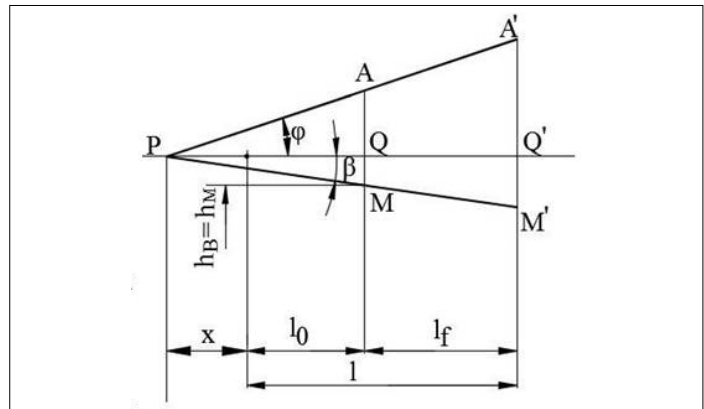

Figure 4. Longitudinal section of a three-point linkage.

Table 1. Markings of the connection points for threepoint linkage

\begin{tabular}{|l|c|l|c|}
\hline $\begin{array}{c}\text { Connection points of the } \\
\text { upper link }\end{array}$ & \multicolumn{2}{c|}{$\begin{array}{c}\text { Connection points of the } \\
\text { lower link }\end{array}$} \\
\hline Marking & $\varphi\left[^{\circ}\right]$ & Marking & $\beta\left[^{\circ}\right]$ \\
\hline T_lower & 15 & V_lower & 0 \\
\hline T_middle & 10 & V_middle & 5 \\
\hline T_upper & 5 & V_upper & 10 \\
\hline
\end{tabular}

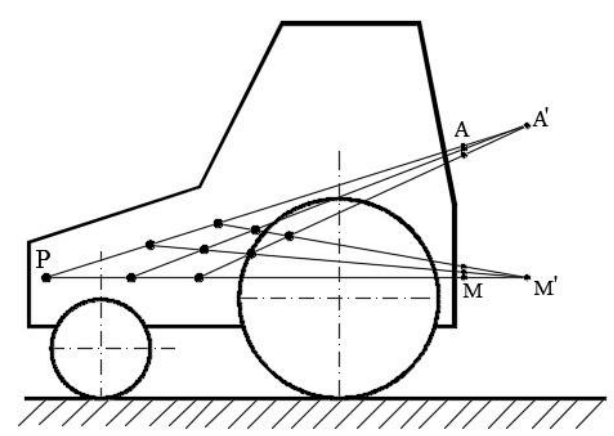

Figure 5. The position of the instantaneous vertical pivot point as a function of the connection of the three-point linkage
The force $R_{K}$ under the depth limit wheel can be calculated from equation :

$$
R_{K}=\frac{G_{E} \cdot\left(x+l+l_{G}\right)+F_{z} \cdot\left(x+l+l_{F}\right)-F_{x}\left(h_{F}+h\right)}{x+l_{K}+l+f \cdot h} .[N]
$$

Symbols of equations (4) and (5) are: $x$ the distance of the instantaneous vertical pivot point $P$, from the driven rear axle [m]; $h$ is the difference in level of the instantaneous pivot point $\mathrm{P}$ from the ground [m]; $l, l_{\rho} l_{G}, l_{K}$ are the lengths to be followed in Figure 3. [m]; $l_{F}$ and $h_{F}$ are the distances determining the point of attack of the ground resistance on the work machine [m]; $f$ is the rolling coefficient, based on [2].

Equation (5) points to the factors influencing the $R_{K}$ soil resistance force. In this dissertation we study the effect of the connection points of the upper link and the lower link, which are reflected in the data $x, h$.

The connections between $x$ and $h$ were determined on the basis of the draft of the longitudinal section, (Figure 2), of the three-point linkage, Figure 4.

$$
\begin{aligned}
& x=\frac{A^{\prime} M^{\prime}}{\operatorname{tg} \varphi+\operatorname{tg} \beta}-l_{O}-l_{f}[\mathrm{~m}] \\
& h=h_{B}+\left(x+l_{0}\right) \operatorname{tg} \beta[\mathrm{m}],
\end{aligned}
$$

where:

$-\varphi$ is the angle characterizing the various connections of the upper support link $\left[^{\circ}\right]$;

$-\beta$ is the angle from the lower link connection ${ }^{\circ}{ }^{\circ}$;

$-h_{B}$ and $l_{0}$ are the traceable lengths in Figure 3. [m];

$-A^{\prime} M^{\prime}$ is the height of the working plane $A^{\prime} B^{\prime} C^{\prime}$ of the three-point linkage [m]. This height dimension is standardized, based on [4].

The fixation of the links can be changed (Figure 2). We also changed the connection points of the upper link and of the lower link. Table 1. summarizes the markings of the connection points and the dimensions of the angles assigned to them.

The connection points of the upper link change the degree of the angle $\varphi$. The upper link is fixed at the lower, middle and upper connection points, so that the angle $\varphi$ is considered to be $15^{\circ}, 10^{\circ}$ and $5^{\circ}$ (Table 1 ).

The connection points of the lower link change the degree of the angle $\beta$. The lower, middle and upper connection points are examined, and accordingly the values of the angle $\beta$ are considered to be $0^{\circ}, 5^{\circ}$ and $10^{\circ}$ (Table 1 ). 
The position of the instantaneous pivot point $P$ as a function of the three connection positions of the upper link and the three connection positions of the lower links is presented in Figure 5.

The connection points of the links affect the position of the vertical instantaneous pivot point $P$. The higher the links are fixed, the higher the $P$ point will be located (Figure 5).

We examined the conformation of the $R_{K}$ force under the depth limit wheel as a function of the three connection points of the upper link and the lower link. Data used: PP3-30 plow size, II category three-point linkage equipment, dimensions according to ISO 730-1, based on [4] and the sizes of the U650 power machine.

The lower attachment point of the lower link and the raising of the upper link cause an increase in the $R_{K}$ force (Figure 6). This means that the work machine relies more on the ground. The increase in the $R_{K}$ force means that the driven wheels of the tractor have a smaller additional weight, thus the effect of increasing the adhesive weight force of the work machine is smaller (Figure 7).

The $G_{a d h}$ force changes as a result of the suspension. It can be calculated from equations (2) and (3):

$$
G_{a d h}=G_{T}+G_{E}+F_{z}-R_{k} \quad[\mathrm{~N}] .
$$

The markings in relation (8) are the same as the markings of (3).

The change in $G_{a d h}$ adhesion weight force due to the connection of the three-point linkages connection points is shown in Figure 7.

Adhesion weight force affects the tractive force. The maximum tractive force was calculated with the relation (1), where $\mu=0,4$ was used, based on [1]. The change in tractive force as a function of the connection of the links is shown in Figure 8.

The change in maximum tractive force as a function of the suspended work machine and the links connection is shown in Table 2 and Figure 9.

The greatest increase in tractive force is caused by the connection where the angle between the links is the greatest, in this case the lower connection point of the upper link and the upper connection point of the lower link.

\section{Conclusions}

The connection points of the three-point linkage affect the position of the instantaneous vertical pivot point $P$.

The magnitude of the soil resistance under the depth limit wheel of the suspended work machine varies due to the connection of the links of the
Table 2. Effect of three-point linkage connection on tractive force of the studied power machine and suspended work machine system

\begin{tabular}{|l|l|l|l|}
\hline $\begin{array}{c}\text { Effect of } \\
\text { connection }\end{array}$ & \multicolumn{1}{|c|}{$\begin{array}{c}\text { V_upper } \\
\text { \% }\end{array}$} & \multicolumn{1}{|c|}{$\begin{array}{c}\text { V_middle } \\
\text { \% }\end{array}$} & $\begin{array}{c}\text { V_lower } \\
\text { \% }\end{array}$ \\
\hline T_lower & 13,81 & 11,97 & 9,41 \\
\hline T_middle & 12,93 & 10,59 & 7,22 \\
\hline T_upper & 11,85 & 8,81 & 4,28 \\
\hline
\end{tabular}

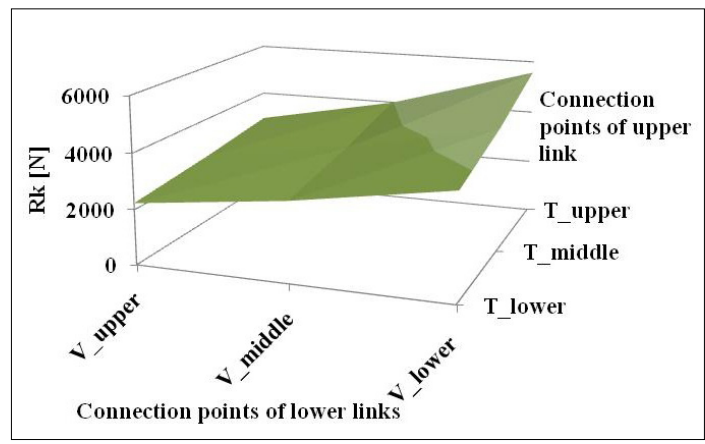

Figure 6. Effects of the three-point linkages connection points on the $R_{K}$ force

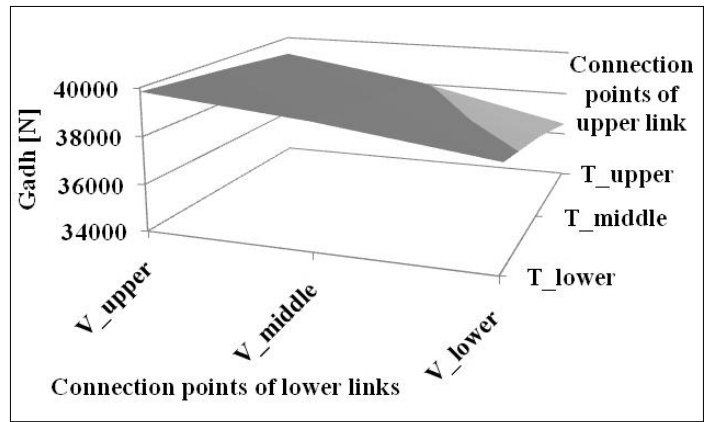

Figure 7. Effects of the three-point linkage connection points on adhesive weight force

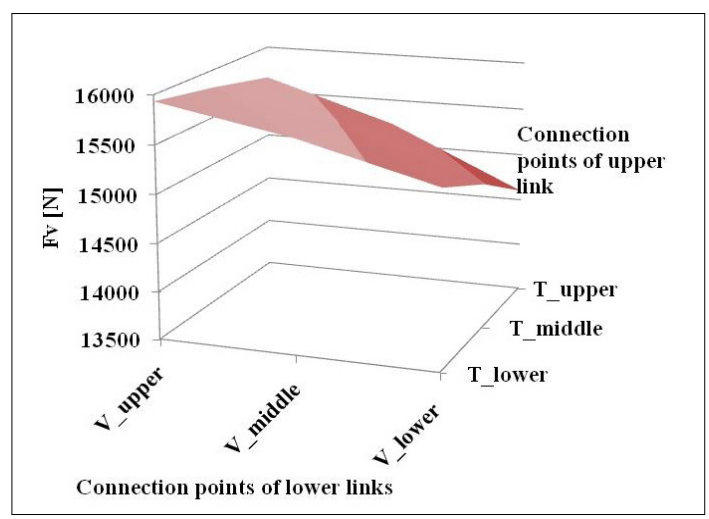

Figure 8. Effects of three-point linkage connection points on tractive force 


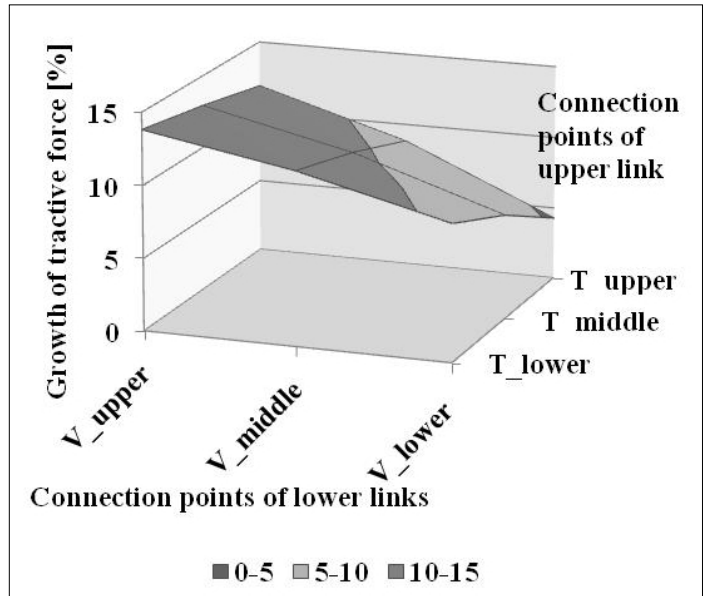

Figure 9. Growth rate of the traction force

three-point linkage at different points. The lowest ground resistance produces the greatest supplementary weight effect. This can be achieved by lowering the upper link and connecting the lower link to the upper point. Thus, the closer the instantaneous vertical pivot point $P$ is to the rear axle, the greater the supplementary weighting effect of the suspended work machine. Both the adhesive weight force and the tractive force are greatest here for the suspended work machine.

By differently connecting the links of the threepoint linkage, the suspended work machine, under the conditions studied, elicits an increase in tractive force by $4.28-13.81 \%$.

The mathematical models illustrate and explain the phenomenon; they are suitable for further research, to examine the performance of the power take-off and the development of fuel consumption as a result of the connection of the threepoint linkage.

\section{References}

[1] Szendrő P.: Géptan. Mezőgazda Kiadó, Budapest, 2003. 96-191.

[2] Ormenisan A. N.: Theoretical and experimental research concerning the influence of automatic control systems of the tractor linkage mechanisms on the dynamics and energetics of ploughing units. Summary of PhD Thesis, UTBV, Brassó, 2014. 20-25.

[3] Máté M.: Müszaki mechanika - kinematika. Erdélyi Múzeum-Egyesület, Kolozsvár, 2010. https://doi.org/10.36242/mtf-10

[4] Varga V.: Az univerzális traktorok vonószerkezete és hárompont-függesztő szerkezete. Agrofórum, 19/7. (2008) 88-91. 